\title{
Cena
}

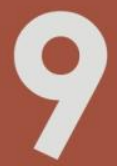

Dossiê Dança em Desdobramentos

PERIÓDICO DO PROGRAMA DE PÓS-GRADUAÇÃO EM ARTES CÊNICAS

INSTITUTO DE ARTES | DEPARTAMENTO DE ARTE DRAMÁTICA

UNIVERSIDADE FEDERAL DO RIO GRANDE DO SUL

\section{A PERCEPÇÃO DO BAILARINO DE DANÇA CONTEMPORÂNEA SOBRE "SER BAILARINO"}

Aline Nogueira Haas

Professora do Curso de Licenciatura em Dança. Departamento de Educação Física - UFRGS. Vice-líder do Grupo de Estudos em Arte, Corpo e Educação

Bruna do Nascimento Carrasco

Licenciada em Educação Física pela Faculdade de Educação Física e Ciências do Desporto - PUCRS

Martina Bevilacqua

Aluna do Curso de Licenciatura em Dança - UFRGS. Integrante do Grupo de Estudos em Arte, Corpo e Educação.

Ângela Cristina Bugs Gonçalves

Aluna do Curso de Licenciatura em Dança - UFRGS. Integrante do Grupo de Estudos em Arte, Corpo e Educação.

Gabriel de Negreiros Ketzer

Aluno do Curso de Bacharelado em Educação Física UFRGS. 


\begin{abstract}
RESUMO: Este artigo tem como objetivo analisar a percepção do bailarino de dança contemporânea com relação a "ser bailarino" e identificar as implicações de ser bailarino na sociedade atual. Ele apresenta considerações resultantes de uma investigação de campo, descritiva e de cunho qualitativo. Os sujeitos de pesquisa foram sete bailarinos que atuam profissionalmente na área da dança contemporânea na cidade de Porto Alegre, Rio Grande do Sul. Verificamos que a tendência da sociedade atual é não aceitar primeiramente a profissão de bailarino, tratando-se de um indivíduo do gênero masculino, mas depois do reconhecimento dessa atividade, tanto sociedade, quanto família e ciclo de amizades aprovam essa profissão e orgulham-se dos homens bailarinos. Os bailarinos entrevistados enfatizam o amor pela dança e pela sua profissão, na qual, apesar das dificuldades iniciais e dos preconceitos, sentem-se realizados profissionalmente.
\end{abstract}

PALAVRAS-CHAVE: Dança Contemporânea; Bailarino; Gênero; Corpo.

\begin{abstract}
The goals of the study are to analyze contemporary dancers' perceptions' in relation "to being a dancer" and to identify the implications of being a "dancer" in today's society This article presents considerations resulting from a field investigation, descriptive and qualitative nature. The subjects were seven dancers who work professionally in the field of contemporary dance in the city of Porto Alegre, Rio Grande do Sul. We verified that today's society tendency is, initially, not to accept dancer as profession in the case of a male individual. But after the recognition of this activity, the society, the family and the circle of friends approve this profession and are proud of these male dancers. The interviewed dancers emphasized their love for dance and the profession, in which, despite initial difficulties and prejudices, they feel professionally fulfilled.
\end{abstract}

KEYWORDS: Contemporary Dance; Dancer; Gender; Body.

\title{
1. INTRODUÇÃO
}

Atualmente, é comum encontrar bailarinos do gênero masculino nas escolas de dança, porém esse fato ainda gera muitas discussões dentro e fora do âmbito científico e acadêmico.

Desde o ensino escolar básico costuma ocorrer uma divisão evidente entre atitudes ditas femininas e atitudes ditas masculinas, como, por exemplo, professores ou pais que utilizam frases como "homem não chora" e "homem não dança". A partir daí, pode-se criar uma imagem preconceituosa de garotos que dançam. Além disso, a divisão de amizades acontece na escola quase que exclusivamente pelo gênero, existindo pouca interação entre meninos e meninas, até mesmo nas aulas. Um exemplo disso é quando meninos e meninas realizam atividades distintas na aula de Educação Física ou em outros momentos dentro 
da escola, gerando valores de intolerância uns com os outros. Outro aspecto a ser considerado é a distinção já realizada pelos símbolos presentes na nossa vida cotidiana, como, por exemplo: a saia é sempre relacionada ao gênero feminino; o futebol é sempre relacionado ao gênero masculino; e, assim por diante (GIUSEPPE; ROMERO, 2004).

Giuseppe e Romero (2004) também constataram, através de um estudo feito com entrevistas, alguns comentários bastante preconceituosos com relação a homens que dançam: "quando o homem pratica a dança fica afeminado, com jeito de garotinha" (p. 145); ou, quando questionados sobre a relação da dança com a masculinidade, um dos entrevistados disse: "para ser macho tem que ser viril, não negar fogo, então não tem nada a ver com dança, que deve ser suave, frágil e leve" (p. 145).

No entanto, mesmo que preconceitos e distinções sociais existam, a figura masculina é indispensável à dança (ACHCAR, 1998, apud SOARES; ASSIS; SOUZA; 2007). Um exemplo disso é o Pas de Deux, dançado por um homem e por uma mulher, símbolo da sexualidade heterossexual dentro do Ballet Clássico, no qual o homem conquista a mulher, a sustenta e manipula, com a função de protegê-la. Esse momento da dança envolve o toque entre os parceiros, sendo esta, normalmente, a primeira forma de comunicação entre humanos (HANNA, 1999).

Analisando-se aspectos históricos da dança, depois da Revolução Francesa homens famosos passaram a dançar, e a dança foi divulgada como uma atividade masculina. Dentro da dança os próprios homens se transvestiam, assumindo o papel das mulheres, iniciado por Luís XIII (KISSELGOFF, 1986, apud HANNA, 1999). Isso acontecia porque, segundo a sociedade, mulheres bem-educadas não poderiam aparecer em papéis públicos. Segundo Santos e Almeida (2008), a dança teve seu auge com o rei Luis XIV, chamado de "O Rei Sol", que aos 12 anos dançou com o balé da corte e, a partir disso, sempre dançava em Ballets como uma figura de poder, de Deus.

Apesar disso, ocorreu, com o passar dos anos, um declínio da figura masculina no Ballet Clássico. De acordo com Hanna (1999), os laços entre bailarinos e nobres se romperam, fazendo a dança decair e diversos homens desistirem da profissão. Nesse momento, as mulheres ganharam maior 
importância e espaço na dança e passaram a ser protagonistas das obras coreográficas. Segundo Fortin (2003), no Canadá, dos 6.000 artistas profissionais da dança, $80 \%$ são mulheres, isso tudo devido à imagem estereotipada que a bailarina tem de ser jovem, bonita e feliz.

A partir dessas constatações, surgiram os seguintes questionamentos: Qual é a percepção do bailarino de dança contemporânea em relação a 'ser bailarino'? Quais são as implicações de ser bailarino dentro da sociedade atual? Dessa forma, esta pesquisa tem os seguintes objetivos: analisar a percepção do bailarino de dança contemporânea com relação a "ser bailarino" e identificar as implicações de ser bailarino na sociedade atual.

Para responder a esses questionamentos e aos objetivos do estudo, permeamos as discussões teóricas nas ideias de autores que abordam a temática de gênero e dança (FRAGA, 1995; STINSON, 1998; HANNA, 1999; GIUSEPPE e ROMERO, 2004; SOARES et AL; 2007; SANTOS, 2009; ANDREOLI, 2010; DIOGO, 2010); e, corpo na dança (FORTIN, 2003; PRIMO, 2006; GIL, 2005).

\section{CAMINHOS METODOLÓGICOS}

Este estudo se caracterizou por ser uma pesquisa de campo, descritiva e de análise qualitativa.

Os sujeitos de pesquisa foram sete bailarinos de dança contemporânea que atuam profissionalmente na cidade de Porto Alegre, Rio Grande do Sul. Todos os participantes da pesquisa assinaram um termo de consentimento livre e esclarecido, que consente a sua participação no estudo.

O instrumento de coleta de dados utilizado foi uma entrevista individual semiestruturada com perguntas abertas, que foram gravadas e, posteriormente, transcritas com fidelidade, sem alterações dos vocábulos utilizados. As mesmas foram realizadas em diferentes locais, de acordo com a preferência e possibilidade de cada entrevistado, conforme agendamento. Realizamos uma conversa informal procurando seguir o roteiro de entrevista estabelecido, alterando-o quando necessário, de acordo com o entrevistado. A entrevista foi gravada, sem interrupções, para anotações de informações, sendo as perguntas realizadas da forma mais clara possível e tentando mantê-la como um diálogo 
rotineiro, da forma mais natural possível, parecendo uma conversa informal e priorizando a veracidade das informações a serem obtidas.

Para manter o sigilo das identidades dos bailarinos que participaram do estudo, eles foram identificados com números de 1 a 7.

Para a análise das narrativas dos sujeitos de pesquisa, as falas foram agrupadas de acordo com duas categorias de análise: o bailarino de dança contemporânea na sociedade atual: reações e comportamentos; e, a percepção do bailarino de dança contemporânea com relação a "ser bailarino".

Os dados obtidos na análise foram discutidos com os referenciais teóricos estudados, interligando as histórias, opiniões, percepções e sentimentos dos sujeitos de pesquisa, procurando dar um parâmetro geral de como é a percepção do bailarino de dança contemporânea com relação "a ser bailarino" e de como a sociedade (amigos, familiares, colegas de trabalho) reage e se comporta em relação a esse tipo de atividade profissional.

\section{O BAILARINO DE DANÇA CONTEMPORÂNEA NA SOCIEDADE ATUAL: REAÇÕES E COMPORTAMENTOS}

A grande maioria dos entrevistados contou que no início da sua prática na dança as pessoas estranhavam bastante a ideia de um homem estar dançando, mas todos falaram que, atualmente, não têm problemas com essa situação e que as pessoas são bastante receptivas em relação ao seu trabalho com a dança.

Os entrevistados comentam ainda que no início do contato com a dança existe a questão do preconceito, mas que esta foi superada quando seus amigos e familiares os viram dançando: "[...] quando as pessoas olham eu dançando ou o meu grupo dançando acham tudo muito bonito entendeu? A partir daí eles começam a gostar, porque tem muita gente que não conhece a dança entendeu? [...]" (Entrevistado 2); "[...] eu tenho tido bastante força das pessoas que conhecem, que acreditam no meu trabalho [...]" (Entrevistado1).

Nesse sentido, Fraga (1995) mostra que essa visão é reproduzida desde a infância. Em estudo realizado, o autor dividiu alunos de uma escola e trabalhou a dança nas aulas de Educação Física. Primeiramente os meninos não gostaram da ideia, pois relacionaram a palavra dança ao Ballet Clássico, por sua vez 
relacionado a uma atividade exclusivamente feminina e delicada. Os ritmos trabalhados na dança foram Dance Music e Tango e, no decorrer das aulas, os meninos se desprenderam gradativamente, se identificaram e localizaram seu papel na dança, deixando de lado a dúvida se a sua masculinidade estava sendo questionada ou não.

Giuseppe e Romero (2004) também relatam que esta estranheza causada em relação aos homens realizarem atividades ditas femininas começa desde cedo, exemplificando que a dança é uma atividade feminina e não masculina nas aulas de Educação Física desde as séries iniciais, ou seja, as mulheres a praticam e os homens não. Cabe ao professor livrar-se desse tipo de preconceito e propor atividades que envolvam a dança para ambos os gêneros, fazendo, assim, com que os homens pratiquem a dança. Dessa forma, o professor de Educação Física irá formar cidadãos mais esclarecidos e menos preconceituosos, contribuindo para o rompimento da imagem do homem que "não pode dançar", "chorar" e, tampouco, expressar seus sentimentos.

Em seu estudo, Wenetz e Sttiger (2008) afirmam que a diferenciação dos gêneros não é exclusiva da educação formal, pois em espaços formativos, como o recreio escolar, também existem atividades separatistas que reafirmam os estereótipos de atividades femininas e atividades masculinas.

Oliveira (2010) reforça a ideia anterior de que existe falta de abertura para os estudantes discutirem sobre gênero e sexualidade dentro da escola, ainda que estes conteúdos sejam obrigatórios e ministrados para jovens, adultos e idosos. Mesmo que diversos conteúdos escolares estejam relacionados com essas temáticas, não existe instigação da parte do professor em relação aos mesmos, ocorrendo até negação da parte dele.

Ainda assim, para mostrar que é possível mudar a imagem de que a dança é uma atividade feminina, utilizamos o dado trazido por Primo (2006), no qual é descrito o preconceito que era sofrido por mulheres que dançavam Ballet Clássico no surgimento dessa técnica, sendo estas comparadas a prostitutas. Essa imagem conseguiu se apagar, e hoje as mulheres bailarinas são vistas como mulheres longilíneas e belas.

Outro fator a ser destacado, nos resultados obtidos, é que dois bailarinos acreditam que existe uma falta de legitimação em relação à dança como uma 
profissão, sendo considerada apenas uma atividade de lazer que, segundo o estudo de Salles-Costa et al (2003), é mais procurada por mulheres. Dessa forma, existe uma tendência à falta de credibilidade por parte da sociedade, dos amigos e dos familiares. Em relação à escolha dessa profissão, desacreditam que esse é o seu trabalho, como coloca o entrevistado 7, que busca demonstrar e explicar como é o seu trabalho, para buscar o entendimento da sociedade: "[...] pras pessoas entenderem, eu digo que trabalho com arte, aí que trabalho com pesquisa de movimento aí depois é que eu chego na dança[...]". É importante ressaltar que, apesar de o profissionalismo na dança ter surgido no século XVIII, através da criação dos elementos técnicos que iriam compor o Ballet Clássico, feita por Charles-Loius-Pierre (BOUCIER, 2006), ainda hoje, em alguns países, entre eles o Brasil, a dança não alcançou sua legitimidade perante a sociedade. Essa desvalorização da profissão está atrelada diretamente a questões históricas.

Destaca-se também que o entrevistado número 7 comenta a preocupação da família com o retorno financeiro da profissão: "[...] Acharam que eu era louco, que eu ia passar fome [...]. Quando começaram a vir os resultados, quando eles começaram a me ver no palco, aí veio o reconhecimento geral [...]". Santos (2009, p. 55) afirma que "a profissionalização da dança não possui prestígio em nossa cultura e, para um homem encaminhar seu futuro dentro dessa área, levanta suspeitas se não atingir um futuro promissor e de sucesso". Em sua pesquisa apenas um dos dez entrevistados pretende ter a dança como fonte principal de renda futuramente.

Ainda em relação à reação da família quanto à prática da dança, houve uma divisão, em que algumas famílias apoiaram a decisão de entrar para o campo de atuação da dança e outras foram contra. Entre as que apoiaram, existe o caso do entrevistado número 6 , por exemplo, que começou com a dança gaúcha, tipo de dança na qual a presença masculina é muito forte e bem vista, já que é tradição no Rio Grande do Sul. Ele diz: "[...] quando eu comecei a dançar não tive nenhum problema porque eu comecei no folclore, por ser uma coisa gaúcha, uma coisa de macho, uma coisa de homem, eu não tive problema [...]". De acordo com Santos (2009), a escolha por outro estilo de dança, diferentemente dos tradicionalmente masculinos, colocam em questionamento a sua masculinidade nata. 
Destacamos ainda as seguintes falas que demonstram o apoio recebido pelas famílias dos bailarinos: "[...] A minha família me apoiou desde o início, não teve nenhum problema [...]" (Entrevistado 1), "[...] Por incrível que pareça assim foi bem normal, super tranquilo assim [...]". (Entrevistado 5), "[...] Primeiro teve muito preconceito né, mas não com relação a minha família, minha família me deu o maior apoio [...]" (Entrevistado 3).

Os entrevistados cujas famílias não aceitaram o início de seu contato com a dança sempre enfatizam que atualmente as famílias apoiam a escolha dessa profissão, afirmando que a negação foi somente no início, como podemos constatar na seguinte fala: "[...] foi ver uma apresentação minha e gostou bastante e começou a me apoiar tipo, viu que eu tinha talento [...]" (Entrevistado 2).

Foram citados também casos de preconceito diretamente do pai, figura masculina da casa que quer que o filho também represente uma figura máscula e acha que dançando isso não é possível: "[...] a família não aceitava muito bem. $O$ pai era contra, porque homem dançar é complicado [...]" (Entrevistado 4).

O estudo de Santos (2009) também aponta que a presença da figura paterna é um motivo de preocupação dos bailarinos, uma vez que estes não aceitam a atividade e tentam vetar a prática. Assim como no estudo de Andreoli (2010), que também salienta a oposição paterna a essa prática. O autor coloca:

O obstáculo familiar aparece frequentemente atrelado a essa associação entre a dança e homossexualidade, num sentido negativo, ou seja, dentro de um registro simbólico de heteronormatividade e homofobia (2010, p.86).

Em relação aos amigos, todos os bailarinos entrevistados sofreram preconceitos iniciais em seus núcleos de amizades, sendo estes superados depois de um tempo de prática: "[...] Meus amigos no começo tinham um pouco de vergonha, porque sempre tem o preconceito né [...]" (Entrevistado 2). "[...] Alguns amigos no começo assim começaram a rir, tem aquela história do Ballet né, tem que ser veado pra dançar Ballet, e não é verdade, veado tem em todas as áreas [...]" (Entrevistado 5). A realização de uma tarefa dita feminina traz uma inferiorização do bailarino, uma vez que socialmente as mulheres têm menor reconhecimento. De outro lado, a realização de tarefas historicamente ditas masculinas por mulheres são incentivadas, pois procura-se uma ascensão do papel social da mulher (STINSON, 1998). 
Como já explicitado anteriormente, o preconceito com a dança acontece desde o seu surgimento. Antigamente, o preconceito era com as mulheres, pois no início do profissionalismo dessa arte eram somente os homens que dançavam, vestindo-se de mulheres para fazer os papéis femininos, já que, perante a sociedade, não era permitido que mulheres educadas atuassem em espetáculos e representassem papéis públicos (KISSELGOFF, 1986 Apud HANNA, 1999).

Podemos perceber, assim, através dos depoimentos dos entrevistados, que o preconceito em relação "a ser bailarino" ainda existe na sociedade atual, mas agora em relação à figura masculina, partindo não apenas de pessoas da sociedade em geral, mas também das pessoas de seu convívio diário como a família e os amigos. Porém, quando essas pessoas percebem que tal atividade não influencia na forma de ser e no cotidiano da amostra estudada, vendo-os brilhando e felizes, começam a apoiá-los, pode nos fazer perceber que a barreira do preconceito é vencida através do prazer e satisfação que a atividade traz para os mesmos.

\section{A PERCEPÇÃO DO BAILARINO DE DANÇA CONTEMPORÂNEA COM RELAÇÃO A “SER BAILARINO”}

Ao serem questionados em relação a "ser bailarino", todos os entrevistados demonstraram segurança na escolha de sua profissão, manifestando devoção e amor incondicional a dança, sendo essa atividade motivo de felicidade, realização e o que os complementa: "[...] Pra mim a dança é a minha felicidade, porque se eu não tô dançando eu não tô feliz [...]” (Entrevistado 2);“[...] Pra mim ser bailarino é tudo. É um prazer assim inexplicável [...]" (Entrevistado 3); "[...] é uma coisa que me faz feliz, que eu gosto de fazer, que me satisfaz e me realiza [...]" (Entrevistado 4); "[...] Realizado, eu sou uma pessoa realizada, faço aquilo que acredito e aquilo que tenho vontade de fazer, então eu me sinto realizado assim, significa realização... profissional, pessoal e artística [...]" (Entrevistado 7).

Indo ao encontro dos resultados apontados, Hanna (1999) diz que o bailarino compreende através da dança as emoções e os sentimentos humanos, ajudando a construir sua mente e linguagem corporal, aprendendo a ter controle sobre si mesmo e expandindo e demonstrando seus sentimentos, chegando a uma sensação de liberdade. Talvez por isso essa seja uma atividade tão 
prazerosa para quem vive nela, pois o bailarino utiliza essa forma de linguagem corporal para expressar seus sentimentos, "desabafando" através do movimento dançado, como se fosse uma "sessão de terapia dançada", prazerosa, libertadora.

A dança tem espaço para todos que querem vivê-la, seja qual for o seu estilo de vida, seu gênero ou sua sexualidade, existindo, dessa forma, uma grande procura de gays pela dança. Isso se deve à involuntária procura dos seres humanos a ambientes em que eles se adaptem facilmente ou em grupos em que são "permitidos pela sociedade" a se integrarem. Nos Estados Unidos da América, mulheres e gays eram bastante discriminados, o que os fez procurar na dança uma fuga para seus constrangimentos sociais e econômicos (HANNA, 1999).

Ainda de acordo com a autora, a dança atrai bastante o público homossexual, porque é o momento que essas pessoas têm de demonstrar sua sensibilidade, tornando-se membros da sociedade igual a outros ao interpretar o papel de homem heterossexual que não poderiam viver no seu cotidiano. Através da dança, os bailarinos gays aumentam a sua autoestima e são aprovados naquele meio que passam a viver. Ao relacionar-se com a sociedade, o indivíduo tem a capacidade de influenciar na mesma e com isso fortalecer seu autoconceito. Para isso deve haver uma comunicação subjetiva através do movimento expressivo (LIBERMAN, 2002).

Constatamos também nos depoimentos dos entrevistados que muitos não conheciam a dança e, quando tiveram seu primeiro contato com ela foi, normalmente, como público, sentindo-se atraídos por essa prática, apaixonandose e entregando-se a ela, independente de sua sexualidade.

De acordo com Sampaio (2001), nosso corpo representa exatamente o que somos e o que queremos ser. Em um trabalho corporal, o corpo deve ser utilizado como um todo, em diferentes formas de experimentações, e ser respeitado em suas particularidades. Fortin (2003) corrobora essa ideia, pois acredita que a dança é constituída basicamente pelo corpo em movimento, e a construção de cada corpo depende, além do próprio indivíduo, da técnica de dança que ele realiza.

A partir disso, é importante compreender que a construção do corpo do bailarino e de sua linguagem acontece através do processo de aculturação, em 
que duas culturas (a do bailarino e do corpo o qual ele almeja) intercambiam elementos para o desenvolvimento da cultura inicial, no caso a do homem bailarino. Através da prática e do desenvolvimento da técnica de dança, o indivíduo apreende tanto um "corpo físico", no qual desenvolve a sua sensibilidade e a capacidade técnica de representação no palco, como também um "corpo social" proveniente da adaptação social entre o bailarino e a sociedade vigente. De acordo com Douglas (1970, apud GASTALDO, 2001), esse processo ocorre através da "experiência física do corpo", momento em que há interferência no espaço físico e social:

O corpo social determina o modo segundo o qual o corpo físico é percebido. A experiência física do corpo, sempre modificada pelas categorias sociais através das quais ele é percebido, sustenta uma visão particular de sociedade. Há um câmbio contínuo de significados entre os dois tipos de experiência corporal, de modo que cada um reforça as categorias do outro (DOUGLAS, 1970, p. 65, apud GASTALDO, 2001, p. 205).

Com isso, podemos reafirmar que "É a cultura que humaniza a espécie e o faz em sentidos muito diferentes" (HEILBORN, 1997, p.2). Louro (2000) colabora com essa ideia ao colocar que as marcas inscritas culturalmente no corpo diferenciam, e, por isso, criam identidades que, se não seguem uma normativa, são discriminadas pela sociedade.

O corpo tem sempre uma grande representação social dentre as pessoas, de acordo com suas diferentes épocas e locais. Para os gregos, por exemplo, os deuses representam o corpo ideal, e são referências para o homem, tendo sua estética voltada para a conquista do corpo perfeito e de ser uma pessoa saudável através da prática de esportes. Já no Egito, o povo disseminava a ideia da imortalidade através do ritual de mumificação dos corpos e, através da pintura, tentavam representar uma forma real do corpo. Para isso acabavam distorcendo as imagens, colocando rosto, braços e pernas desenhados de perfil e tronco e olhos desenhados de frente. Para os romanos, o homem é um ser dentro da sua normalidade, então o representam com suas imperfeições, mantendo a naturalidade (GIL, 2005).

Além dos aspectos apontados, constatamos que os motivos pelos quais os bailarinos entrevistados decidiram entrar no campo de atuação da dança são diversos, quais sejam: ver uma apresentação de dança e gostar; parentes que 
dançavam; e motivos pessoais. Esses motivos são ilustrados nos seguintes trechos das entrevistas: "[...] o primeiro contato que tive fui convidado pra assistir um grupo de folclore dançando e meus amigos gostando e a partir dali comecei a dançar [...]" (Entrevistado 6), "[...] Eu vi uma apresentação de dança, antes eu nem conhecia a dança, pensava como os outros, mas daí até que eu vi uma apresentação com 11 anos, de jazz dance, e gostei muito [...]" (Entrevistado 2); "[...] Minhas duas irmãs são bailarinas e eu assisti um espetáculo de final de ano de uma delas que foi 'A Bela Adormecida', e eu me apaixonei e disse que era isso que eu queria fazer também [...]" (Entrevistado 4); "[...] Foi uma coisa mais pessoal assim, eu queria tentar superar certos problemas, tipo assim, interiores assim e me expor mais [...]" (Entrevistado 5).

É interessante ressaltar que os entrevistados não se inspiraram em outros bailarinos ou em outros fatores motivacionais externos para a escolha da prática da dança como profissão, mesmo que Porto Alegre tenha três grandes referências masculinas da primeira geração relacionadas ao ensino ou execução da dança: João Luiz Rolla, Rony Leal e Antonio Carlos Cardoso. Homens que, de acordo com Diogo (2010), desde a década de 30 escolheram a dança como profissão.

Ainda que a dança tenha chegado tardiamente na vida da maioria dos entrevistados, todos se sentem reconhecidos pelos seus familiares e amigos atualmente. A dança para eles tem um significado muito importante, sendo seu sustento e sua forma de reconhecimento perante a sociedade.

\section{CONSIDERAÇÕES FINAIS}

Verificamos que a tendência da sociedade é não aceitar primeiramente a profissão de bailarino por se tratar de um indivíduo do gênero masculino, mas, após o reconhecimento da atividade, tanto na sociedade quanto na família e ciclo de amizades, a aprovação dessa atividade acaba ocorrendo. Destacamos também que, em alguns casos, o orgulho e a admiração acabam acontecendo por parte das relações sociais mais próximas (família e amigos).

Os bailarinos entrevistados enfatizaram o amor pela dança e pela sua profissão. Então, podemos perceber que, apesar de dificuldades iniciais, a felicidade com a vida profissional vale a pena para eles e os complementa, pois o 
prazer e a satisfação que a dança proporciona são maiores do que todas as barreiras e os preconceitos que a sociedade impõe.

Identificamos ainda que o bailarino percebe-se como uma "pessoa normal", atuando em uma profissão como qualquer outra. Sua profissão não traz implicações significativas ao seu cotidiano, sentindo-se tratado normalmente pela sociedade e mantendo uma boa relação com ela.

Percebemos que é necessário ampliar o número de estudos científicos acerca do tema de pesquisa e sugerimos a realização de mais estudos na área. Por isso, é importante destacar a importância e relevância desse estudo, pois traz novos conhecimentos científicos sobre uma área ainda pouco pesquisada no Brasil.

\section{REFERÊNCIAS BILBIOGRÁFICAS}

ANDREOLI, Giuliano Souza. Representações de masculinidades na dança contemporânea. 2010. 137 f. Dissertação (Mestrado em Educação). Universidade Federal do Rio Grande do Sul. Programa de Pós-Graduação em Educação. Porto Alegre. 2010. Disponível em: http://www.lume.ufrgs.br/handle/10183/24158. Acesso em: 25 de maio de 2011.

BOURCIER, Paul. História da Dança no Ocidente. São Paulo: Martins Fontes, 2006.

DIOGO, Caroline Duarte. $2^{\circ}$ ato: os homens entram na dança em porto alegre, RS. 2010. 62f. Trabalho de conclusão de curso (Bacharelado em Educação Física). Universidade Federal do Rio Grande do Sul. Porto Alegre. 2010. Disponível em: <http://hdl.handle.net/10183/24915>. Acesso em: 25 de maio de 2011.

FORTIN, Sylvie. Transformações de práticas de Dança. In: PEREIRA, Roberto (Org.). Lições da Dança 4. Rio de Janeiro: UniverCidade, 2003. p.161- 171.

FRAGA, Alex Branco. Concepções de gênero nas práticas corporais de adolescentes.In: Revista Movimento. Ano 2, N.3, 1995/2. p.35-41. 
GASTALDO, Edison Luis. A forja do homem ferro: a corporalidade nos esportes de combate. In: LEAL, Ondina Fachel. Corpo e Significado: ensaios de antropologia social. Porto Alegre: Editora UFRGS, 2001. 2ª Edição.

GIL, José. Movimento Total: O Corpo e a Dança. São Paulo: Iluminuras, 2005.

GIUSEPP, Erik; ROMERO, Elaine. “... Para ser macho não pode negar fogo, tem que ser viril. Então não tem nada a ver com a dança...". In: Revista FACED. N. 8, 2004. p.139-154.

HANNA, Judith Lynne. Dança Sexo e Gênero: Signos de Identidade, Dominação, Desafio e Desejo. Rio de Janeiro: Rocco, 1999.

HEILBORN, Maria Luiza. Gênero, Sexualidade e Saúde. In: UERJ (Org.). Saúde, Sexualidade e Reprodução - compartilhando responsabilidades. Rio de Janeiro: Editora da UERJ, 1997, p. 101-110.

LIBERMAN, Flávia. Trabalho corporal, música, teatro e dança em Terapia Ocupacional: Clínica e Formação. In: Cadernos: Terapia Ocupacional: Produção de conhecimento e responsabilidade social. Centro Universitário São Camilo, São Paulo. V.8, N. 3, jul/set, 2002. p. 39-43.

LOURO, Guacira Lopes. Pedagogias da sexualidade. In: LOURO, Guacira Lopes (Org.). O Corpo educado: Pedagogias da sexualidade. Belo Horizonte; Editora Autêntica, 2000. 2ª Edição.

OLIVEIRA Karina Fürstenau de. Gênero e sexualidade na educação de jovens e adultos: um estudo de caso. 2010. 119f. Dissertação (Mestrado em Educação em Ciências). Universidade Federal do Rio Grande do Sul. Programa de PósGraduação em ciências: química da vida e saúde. Porto Alegre. 2010. Disponível em: http://www.lume.ufrgs.br/handle/10183/26062 Acesso em: 25 de maio de 2011.

PRIMO, Rosa. A Dança Possível: as ligações do corpo numa cena. Fortaleza: Expressão Gráfica e Editora, 2006.

SALLES-COSTA, Rosana; HEILBORN, Maria Luiza; WERNECK, Guilherme Loureiro; FAERSTEIN, Eduardo; LOPES, Claudia S. Gênero e prática de 
atividade física de lazer. Cad. Saúde Pública, Rio de Janeiro. 19 (Sup. 2), 2003. p. S325-S333.

SAMPAIO, Flávio. Ballet Essencial. Rio de Janeiro: Sprint, 2001.

SANTOS, Éderson Costa dos. Um jeito masculino de dançar. 2009. $124 \mathrm{f}$. Dissertação (Mestrado em Educação). Universidade Federal do Rio Grande do Sul. Programa de Pós-Graduação em Educação. Porto Alegre. 2009. Disponível em: http://www.lume.ufrgs.br/handle/10183/21854. Acesso em: 25 de maio de 2011.

SOARES, Jorge Pereira; ASSIS, Yvana Alves de; SOUZA, Fátima Nogueira Gonçalves de. Estudo Comparativo quanto ao gênero e auto conceito de bailarinos e jogadores de futebol amadores do valo do aço. In: Movimentum Revista Digital de Educação Física. V.2, N.2, 2006. p.1-9.

STINSON, Susan. Reflexões sobre a dança e os meninos. In: Pro-Posições. V. 9, N. 2 (26), 1998. p. 55-61.

WENETZ, lleana; STIGGER, Marco Paulo. A construção do gênero no espaço escolar. In: Revista Movimento. V. 12, N.1, 2006. p. 59-80. 